\title{
PRODUÇÃO dO CARNAVAL EM ESCOLAS DE SAMBA: ENSAIO À LUZ DO DEBATE SOBRE ECONOMIA DA CULTURA
}

\author{
Batuque é um privilégio \\ Ninguém aprende samba no colégio \\ (Noel Rosa) ${ }^{1}$ \\ Hoyêdo Nunes Lins² \\ Kamilly dos Santos Ribeiro ${ }^{3}$
}

\section{Resumo}

O Carnaval sobressai na paisagem e na economia da cultura do Brasil, pela sua história, pelo sentido dos festejos principalmente nas grandes cidades - onde o desfile de escolas de samba é preparado durante meses, para participação em concursos -, pelo envolvimento social em diversas comunidades e pela mobilização de volumosos recursos. O artigo ocupase desse tema focalizando um assunto específico: a produção do desfile de Carnaval de uma escola de samba de Florianópolis, a Protegidos da Princesa, a mais antiga agremiação do gênero nessa cidade. A maior parte do texto baseia-se em pesquisa de campo realizada na instituição, no segundo semestre de 2014. As várias etapas da cadeia produtiva do Carnaval da Protegidos são detalhadamente descritas, e alguns reflexos socioeconômicos nas comunidades implicadas são discutidos.

Palavras-chave: Escolas de samba; Economia da cultura; Florianópolis

Classificação JEL: Z19

Versos de Noel Rosa no samba Feitio de Oração, composto em parceria com Vadico em 1932.

2 Professor Titular do Departamento de Economia e Relações Internacionais da UFSC, com participação nos programas de pós-graduação em Economia e em Relações Internacionais dessa universidade. E-mail: hoyedo.lins@ufsc.br

3 Graduada em Economia pela UFSC. E-mail: milly_ribeirol8@hotmail.com 


\section{INTRODUÇÃO}

O tema deste artigo inscreve-se em área que parece ganhar terreno no Brasil: a economia da cultura. Com foco específico e perfil exploratório, o estudo privilegia um importante aspecto da cultura no país, o Carnaval. Mas não se fala desse assunto em termos gerais, e sim no que concerne à produção do desfile das escolas de samba, capturado que foi o Carnaval pela lógica da competição em grandiosos desfiles.

A atenção recai na Protegidos da Princesa, a mais antiga escola de samba de Florianópolis, objetivando-se mostrar como ocorre a produção do seu desfile. Apresentar esse processo também significa tangenciar a problemática dos reflexos socioeconômicos nas comunidades envolvidas, e, por esse ângulo, o tema do artigo faz lembrar aspectos do debate sobre o desenvolvimento na escala local, mormente em meio urbano.

Baseado em pesquisa direta, realizada no segundo semestre de 2014, que permitiu consultas a documentos e realização de entrevistas, o artigo tem três seções além desta introdução e das considerações finais. A seguir fala-se da economia da cultura de um modo geral e da presença do Carnaval. Depois se focaliza a produção dessa festa como aspecto da economia da cultura, utilizando a noção de cadeia produtiva. Em seguida, detalha-se a produção do Carnaval da Protegidos da Princesa, em narrativa instruída pela pesquisa de campo. Por último, abordam-se as interações e os reflexos socioeconômicos dessa produção.

\section{ECONOMIA DA CULTURA: ASPECTOS GERAIS E O ESPAÇO DO CARNAVAL}

Economia da cultura representa campo de pesquisa e formulação de políticas cujo objeto são as atividades de produção, circulação e consumo de produtos e serviços culturais, incluindo a gestão (ROUET, 1998). Sua emergência, com elaborações teóricas relevantes, é recente e não permite retroceder até muito antes dos anos 1960, algo que o escasso interesse da teoria econômica pelo setor e também o contexto ajudam a explicar (TOLITA, 2007).

De todo modo, na segunda metade do século XX, pela crescente importância econômica das atividades culturais em diferentes países e regiões, esse campo cresceu a ponto de frutificar numa associação e num periódico de 
circulação internacional: a Association for Culture Economics International e o Journal of Cultural Economics. Esse percurso refletiu o dinamismo de um período visto como "dourado" (MARGLIN; SCHOR, 1990), com as "indústrias culturais" sendo estimuladas e seus produtos considerados como mercadorias (JAMESON, 1997).

Mas as dificuldades de natureza teórica são importantes. Um aspecto concerne à própria complexidade do assunto, perceptível em esforços de sistematização do conhecimento existente (BENHAMOU, 2007). Para mencionar um ângulo, afeta a reflexão o fato de os objetos no centro das interações sociais possuírem sentidos distintos: o econômico propriamente dito, permitindo quantificações sobre processos produtivos e distribuição (empregos, salários, impostos), e o simbólico, relativo a valores sobretudo culturais e com aspectos até morais e intelectuais, refletindo em atitudes.

A complexidade abrange a delimitação, pois a literatura também fala em "economia criativa". A duplicidade é controversa, mas geralmente se relaciona economia criativa com direitos de propriedade intelectual, mormente autorais. Inserem-se aí segmentos e atividades como desenvolvimento de software, propaganda, moda, design, arquitetura e artesanato, alguns dos quais, exibindo componentes culturais, atingiram grande vitalidade econômica. Mas a articulação com a economia da cultura não é integral, pois nesta a dimensão simbólica cumpre importante papel, ao lado da econômica. Um útil esforço de clarificação dos sentidos está em Friques (2013).

No Brasil, é recente o interesse pela economia da cultura, não obstante a diversidade sociocultural do país, com o que isso significa como potencial. Importante ação para ampliar o conhecimento sobre a produção cultural brasileira foi a elaboração do Sistema de Informações e Indicadores Culturais 2003-2005 (SISTEMA..., 2007), um esforço que se prolongou, pois dois outros documentos do mesmo tipo foram produzidos, o mais recente publicado no segundo semestre de 2013 (SISTEMA..., 2013). As atividades do setor cultural e as profissões e ocupações de natureza tipicamente cultural são identificadas e quantificadas, emergindo dos dados um amplo e diversificado setor cultural no país. Os números sobre o peso dessa economia, quanto às empresas e ao pessoal ocupado, encorpam a percepção sobre o significado da cultura no Brasil.

O Carnaval é uma expressão da cultura, e as atividades enfeixadas na sua realização integram a correspondente economia. O Carnaval expressa a 
cultura porque, de origens remotas em nível planetário (COLAÇO, 1988), e incorporação no século XV pelo calendário da Igreja Católica como festa de excessos logo antes da Quaresma (SEBE, 1986), sua manifestação reflete as condições socioculturais dos ambientes onde ocorre. No Brasil, o perfil europeu (introduzido pelos portugueses) foi mesclado com elementos indígenas e africanos que afetaram especialmente a música: o samba tornou-se o ritmo por excelência, em evolução desde o lundu trazido da África pelos escravos (SODRÉ, 1998).

Há, segundo Queiroz (1992), três períodos básicos na história do Carnaval no Brasil. O primeiro refere-se ao "entrudo", com brincadeiras e comportamentos que, beirando a agressão e vedadas aos escravos, foram proibidos na metade do século XIX (TRAMONTE, 1996). O segundo, relativo ao "grande Carnaval", tinha incidência principalmente urbana e junto às camadas médias e, sobretudo, abastadas da população, capazes de gastos elevados. Aos poucos, a crescente participação de afrodescendentes e outros contingentes fez surgir o "pequeno Carnaval" ou "Carnaval popular".

Nessa terceira fase, aparecem no Rio de Janeiro, nos anos 1920, as escolas de samba, "sociedades civis de cultura e lazer, sem finalidades lucrativas" (QUEIROZ, 1992, p. 74). Criadas em ambientes populares, essas agremiações converteram-se em esferas de prática cultural com reflexos nas relações socioeconômicas e políticas no seu entorno. É a elas que se aplica, antes de tudo, a expressão "mundo do samba", ilustrando a preponderância desse ritmo na coreografia do Carnaval (LEOPOLDI, 1978).

O início dos desfiles das escolas de samba, na metade da década de 1930, deflagrou a trajetória de um evento que depois ganharia o epíteto de "maior espetáculo da Terra". A concorrência, a rivalidade e o simbolismo que permeiam a preparação e a realização desses desfiles tornaram a produção do Carnaval nessas instituições um conjunto grande, complexo, diversificado e oneroso de atividades.

É a produção desses desfiles que, talvez em primeiro lugar, autoriza referir ao Carnaval brasileiro com a expressão "economia da cultura". Mas esta também se justifica para a miríade de atividades associadas às diversas maneiras de participar da festa, fora das escolas de samba e em todas as latitudes do país. 


\section{PRODUÇÃO DO CARNAVAL EM ESCOLAS DE SAMBA: AS- PECTO DA ECONOMIA DA CULTURA NO BRASIL}

A ideia de cadeia produtiva é útil ao estudo da economia da cultura ligada a escolas de samba que, como no Rio de Janeiro, participam de desfiles com sentido de competição. Por cadeia produtiva, conforme Dantas, Kertsnetzky e Prochnik (2002), entende-se a sucessão de etapas interligadas, com transformação e transferência de insumos, até a oferta de um produto, envolvendo divisão do trabalho, conjugação de competências e de recursos diversos e interações de diferentes tipos, abrangências e intensidades.

Tanto quanto as articulações produtivas registradas em outros setores, a preparação dos desfiles das escolas de samba encontra respaldo analítico na ideia de cadeia produtiva porque aquele processo não é outra coisa senão um conjunto de atividades sequenciadas cuja finalidade última é a apresentação oficial. O movimento inteiro pode ser descrito como um "[...] processo cujo desenrolar, etapa por etapa, da pré-produção ao consumo, leva a um produto final, que é consumido por milhares de pessoas ao vivo e milhões de telespectadores no país e no mundo" (PRESTES FILHO, 2009, p. 20).

Uma descrição detalhada da cadeia produtiva da economia do Carnaval em escolas de samba do Rio de Janeiro encontra-se em Prestes Filho (2009). Um grande leque de atividades é considerado, tanto para as escolas de samba do grupo principal - indicando tudo o que se vincula direta e indiretamente à "fabricação" e divulgação do "produto Carnaval" - como para as do grupo de acesso, e também para blocos e bandas. Além disso, são abordados os direitos de propriedade intelectual e da personalidade (como os de imagem), as políticas públicas de investimentos em infraestrutura e incentivo/fomento, a produção de vestimentas, calçados e adereços, as funções comerciais e as providências de cunho social, cultural e socioprofissional. Tudo isso significa envolvimento de numerosos profissionais e empresas e, sobretudo, de incontáveis membros das comunidades, conforme registrado por Feijó e Nazareth (2011).

No que toca às escolas de samba, o centro de gravidade é o barracão, onde se estruturam, organizam e executam diferentes funções. As atividades de "fabricação" do desfile dessas agremiações podem ser condensadas, segundo Prestes Filho (2009), em quatro grupos ou elos de uma cadeia produtiva. 
- $\quad$ p primeiro diz respeito à pré-produção, envolvendo concepção/ criação de enredo, samba enredo, fantasias, adereços e carros alegóricos; nessa etapa são definidos os insumos a serem usados.

- O segundo engloba a produção propriamente dita, com transformação dos insumos em "objetos carnavalescos"; os procedimentos ocorrem no espaço do barracão, em ambientes de atelier e oficina, mobilizando volumosos recursos financeiros e profissionais.

- O terceiro é o da distribuição do "produto", quer dizer, o seu encaminhamento ao mercado para consumo; os meios de comunicação desempenham importante papel nesse processo.

- O consumo, o quarto grande passo, acontece no desfile oficial, com aspectos tangíveis - o desfile em si, o samba, as fantasias e alegorias - e intangíveis - o simbolismo da escola, com sua origem e história e os incrustados laços comunitários e de vizinhança; há consumo também em situações intermediárias ou "intersticiais", como nos ensaios, nos barracões.

Pertencem à órbita da economia do Carnaval as muitas atividades enfeixadas na produção desse entretenimento. As escolas de samba não visam, propriamente, lucro com os desfiles. Grandes recursos são por elas despendidos com o aparente propósito principal de permanecerem "contando histórias" nos desfiles e bem representarem as comunidades de origem, por mais que o sentido mercadológico tenha se apoderado do Carnaval.

Entretanto, a "fabricação" do Carnaval representa elevados ganhos para os setores, segmentos e atividades que formam a tessitura da cadeia produtiva. Isso é evidente nas interações a montante na cadeia, com fornecedores diversos de bens e serviços. Também ganham o trade turístico, a indústria editorial e gráfica, os setores audiovisual e fonográfico, a indústria de instrumentos musicais e o ramo de bebidas, entre outros, pelos impulsos representados pela festa.

Os reflexos são abrangentes. No Rio de Janeiro, Prestes Filho (2009) estimou que o Carnaval de 2006 mobilizou de 450 a 500 mil trabalhadores nas diversas atividades envolvidas, direta e indiretamente. $\mathrm{O}$ faturamento total, derivado dos gastos realizados por pessoas, empresas, associações e órgãos públicos, teria rondado os $\mathrm{R} \$ 700$ milhões, $40 \%$ em remunerações dos trabalhadores. 
Em escala de país, a movimentação financeira do Carnaval atinge a escala de bilhões de reais, considerando-se os grandes centros e também as cidades menores. Em todas elas, a realização da festa, em escolas de samba e em outras modalidades de manifestação, representa dinamização da economia e oportunidades de ocupação e renda. Na Bahia, por exemplo, Salvador à frente, o Carnaval, tornado um evento afro-elétrico-empresarial, segundo Miguez e Loiola (2011, p. 286), “[ [... configurou-se como um mercado que extrapolou os limites da festa carnavalesca propriamente dita".

\section{PRODUZINDO CARNAVAL EM FLORIANÓPOLIS: A ESCOLA DE SAMBA PROTEGIDOS DA PRINCESA}

Aborda-se a produção do Carnaval como aspecto da economia da cultura em Florianópolis focalizando a Escola de Samba Protegidos da Princesa - doravante Protegidos -, uma das agremiações que participam dos desfiles oficiais dessa festa na cidade. Pesou na escolha o fato de se tratar da mais antiga instituição local desse gênero, sendo que as manifestações carnavalescas florianopolitanas têm origem antiga e são diversificadas (CABRAL, 1972; COLAÇO, 1988; RAMOS, 1997; TRAMONTE, 1995).

A Protegidos surgiu em 1948, e seu nome homenageia a Princesa Isabel, signatária da lei que aboliu a escravatura no país. Essa escola de samba teve reconhecida a sua utilidade pública pela Lei Municipal n. 777, de 13/09/1966, ostentando a designação formal de Grêmio Cultural Esportivo e Recreativo Protegidos da Princesa.

Em linha com estudos desse tipo realizados em outros locais, notadamente o Rio de Janeiro, falar em produção do Carnaval na Protegidos implica referir a uma rede de atividades protagonizadas por diversos agentes, ou seja, a uma cadeia produtiva. Seus elos formam engrenagem com divisão do trabalho e desdobramento espacial que, além das imediações, alcança outros ambientes, alguns bem distantes.

Embora o barracão da escola esteja localizado em outro bairro, o espaço imediato das relações, que são cotidianas e do tipo face a face, refere-se ao Maciço Central de Florianópolis, um conjunto de morros que limita o centro da cidade a leste. O processo de ocupação desses morros começou no alvorecer do século XX, produzindo crescentes manchas de habitações precárias, ocupadas por famílias de baixa renda, designadas na retórica 
oficial como Áreas de Interesse Social (LINS, 2011). A comunidade do Morro do Mocotó, uma das maiores desse maciço, é a que mais se envolve com a Protegidos.

Pode-se falar sobre a cadeia produtiva do Carnaval dessa escola nos termos abordados na seção anterior, que salientam a transformação sucessiva e a transferência de insumos entre os vários elos. Por "sequência" não se quer dizer sucessão completa, sem superposições. Paralelismos e concomitâncias crivam o processo, sem comprometer o sentido de encadeamento.

\subsection{Providências iniciais: enredo, samba enredo e pré-produção}

Segundo se observou na pesquisa de campo, o ponto de partida na "fabricação" do Carnaval da Protegidos é a escolha do enredo, quer dizer, do tema da evolução da escola no desfile, ou da "narrativa" protagonizada perante o público. A diretoria administrativa responde por essa tarefa, da qual depende toda a cadeia produtiva do seu Carnaval. A própria organização do desfile, incluindo a disposição das alas, é condicionada pelo enredo.

Definido o enredo, têm início duas atividades distintas, embora conectadas: a pré-produção e a seleção do samba enredo. A primeira abrange as funções de criação/concepção de fantasias, adereços e carros alegóricos. Para as fantasias e adereços, é necessário que o carnavalesco da escola responsável pela criação com base no enredo - desenhe todos os moldes, que são elaborados no próprio barracão. Os desenhos, um para cada ala da escola, passam a compor um "livro" que registra a concepção integral do carnavalesco quanto ao desfile.

Uma cópia desse documento é entregue ao setor de compras dos materiais necessários à produção das fantasias e adereços. As aquisições ocorrem nessa fase inicial, em diferentes mercados, conforme as necessidades. Uma relação obtida na escola permite conhecer a abrangência setorial e geográfica dessas compras:

- Borracha e plástico, geralmente adquiridos em São Paulo;

- Acetato, isopor e espuma, de grande utilização, obtidos no município de São José, na Grande Florianópolis;

- Vestuário e calçados, comprados em Florianópolis ou, quando necessário, em São Paulo; compram-se calçados somente para as 
alas e os quesitos principais: comissão de frente, casal de mestre sala e porta bandeira, bateria e, eventualmente, ala infantil;

- Madeira, utilizada sobretudo nas bases dos carros alegóricos, obtida na região de Florianópolis;

- Tecidos e outros artigos e artefatos têxteis, na maioria para fantasias e adereços; a compra (cerca de $80 \%$ ) é feita em conhecida loja do Rio de Janeiro que oferece diversificado leque de artigos para o Carnaval, constituindo-se num dos maiores fornecedores latino -americanos desses produtos; seu preço nem sempre é o melhor, mas a variedade, a qualidade e a facilidade de crédito a tornam mais atraente do que concorrentes em São Paulo; recorre-se aos segundos só para acessórios não encontrados no Rio de Janeiro, especificamente os de origem chinesa; os $20 \%$ restantes do material provêm de São Paulo ou mesmo da área de Florianópolis;

- Produtos da metalurgia, adquiridos integralmente no município de Biguaçu, na Grande Florianópolis;

- Tintas, todas compradas em Florianópolis;

- Eletroeletrônicos, equipamentos e máquinas, obtidos no comércio da Grande Florianópolis, nas lojas com os menores preços.

Ao mesmo tempo, seleciona-se o samba enredo, geralmente na primeira semana de outubro. A escolha envolve concurso do qual participam vários sambas, e o vencedor é objeto de gravação no Rio de Janeiro, onde os recursos permitem realizar essa tarefa com o necessário nível de adequação e profissionalismo.

A definição do samba é uma etapa especialmente estratégica. Devese levar em conta, além da óbvia vinculação com a "narrativa" do desfile, também a duração deste: oitenta minutos, querendo isto dizer que o samba será cantado cerca de trinta vezes na passarela. Um samba difícil de ser cantado dificilmente agrada ao público, arrefecendo o entusiasmo.

Também pode acontecer de o samba favorecer muito um segmento da escola - como a bateria - sem contrapartida, ou até representando comprometimento, em outros setores, como a comissão de frente. Assimetrias desse tipo devem ser evitadas a todo custo, pois afetam a harmonia do desfile, repercutindo no julgamento 


\subsection{A produção propriamente dita do Carnaval}

$\mathrm{Na}$ fase da produção, as matérias primas e os insumos são recebidos e conferidos no barracão da escola, e têm início as atividades pelas quais tomam a forma de fantasias, adereços e carros alegóricos, conforme as indicações vindas da etapa de concepção/criação. Os moldes das fantasias, sistematizados no "livro" já referido, são enviados para empresa em São Paulo que fornece o arame usado na estrutura de sustentação das vestimentas e adereços. Mas a preparação dessa estrutura exige a montagem de um modelo piloto, que é enviado à escola para a avaliação do carnavalesco. Quando aprovado, esse modelo dá lugar à produção das estruturas, na quantidade especificada.

Uma cópia do mencionado "livro" de moldes é entregue à costureira responsável pelos cortes das fantasias. Geralmente a escola contrata cerca de cinco costureiras para a confecção das fantasias, ficando uma delas incumbida de cortar todo o conjunto, para todas as alas. Executa-se inicialmente um modelo de corte de uma fantasia piloto, para que o carnavalesco examine. Com a sua aprovação, efetua-se o corte de todas as fantasias de cada ala. A abordagem é caso a caso, isto é, ala a ala, cujo número total costuma ser dezenove.

Ocorre de outras costureiras serem contratadas para cortar fantasias de segmentos menores, em geral correspondentes aos quesitos de julgamento no desfile. Assim, uma costureira específica pode fazer serviços em menor quantidade e somente para certas alas ou funções, como para os mestres de bateria e o departamento feminino, entre outros grupos. Outra costureira pode se encarregar só do corte das indumentárias do mestre sala e da porta bandeira. E uma terceira, com atribuição igualmente bem definida, acaba implicada apenas no corte das vestimentas da comissão de frente. Em outras palavras, ao lado do grupo principal de costureiras, atuam profissionais em tarefas de menor escala para atender necessidades pontuais.

Quando prontas, as mencionadas estruturas de arame são enviadas às “aderecistas", que as recebem em suas próprias residências. No período da pesquisa de campo, essas profissionais formavam equipe de dezessete pessoas, encarregadas de decorar aquelas estruturas com os adereços escolhidos pelo carnavalesco e com pedaços de tecidos cortados pelas costureiras. 
Assim como as "aderecistas", também as costureiras trabalham em seus próprios domicílios, distribuídos em comunidades de baixa renda da Grande Florianópolis. No município de Florianópolis, esses locais dizem respeito, além da já indicada comunidade do Morro do Mocotó, também ao Monte Verde (ao norte do centro de Florianópolis, próximo à rodovia SC-401) e à Serrinha (na face oriental do Maciço Central de Florianópolis).

Outro aspecto é que, segundo informado, as fantasias referentes aos quesitos pelos quais a escola será avaliada na passarela, assim como as fantasias das alas, são disponibilizadas aos integrantes somente no dia do desfile. O motivo é claro: por tratar-se de competição, há que preservar o sigilo, o que impõe evitar vazamentos (através de fotos, por exemplo) que representem risco de cópia e, de uma maneira geral, comprometam o atendimento da exigência de ineditismo.

O processo de produção é distinto com respeito aos carros alegóricos, outro importante elemento do desfile. A especificidade tem a ver, por um lado, com a grande necessidade de espaço. O tamanho (sobretudo a altura) das estruturas faz a construção ter lugar integralmente no barracão da escola.

Os procedimentos vinculados a esses carros contam com equipe especializada vinda de muito longe da comunidade local, e mesmo de Santa Catarina. A Protegidos utiliza a competência e a experiência de profissionais do município de Parintins, no estado do Amazonas (na fronteira com o estado do Pará), local conhecido por abrigar um dos mais divulgados e concorridos festivais do Brasil: o Festival Folclórico de Parintins, centrado nos bois bumbás (boi Caprichoso versus boi Garantido), realizado no último final de semana de junho. Soldadores, escultores, serralheiros e decoradores integram essa equipe, responsável pelos carros alegóricos da Protegidos.

Naturalmente, o cronograma cumpre um papel essencial na dinâmica produtiva do Carnaval. A informação obtida durante a pesquisa é que não é possível ultrapassar outubro nas atividades de pré-produção e início da produção. Caso contrário, a evolução da escola no desfile oficial pode ficar sob risco, haja vista a quantidade de providências e detalhes a serem encaminhados e equacionados.

Pelos depoimentos registrados, o processo, na sua integralidade, leva mais ou menos cinco meses, a contar do momento em que o carnavalesco inicia a elaboração dos desenhos das fantasias e adereços. Daí em diante, 
semana após semana, vive-se o frenesi da produção do Carnaval, numa sequência vertiginosa até a data do desfile.

\subsection{Distribuição e consumo do "produto Carnaval"}

A distribuição diz respeito não às fantasias e aos adereços, disponibilizados somente às vésperas do desfile, como se falou, pela necessidade de resguardar o ineditismo. São distribuídos os outros materiais que a escola produz ou faz produzir com vistas à obtenção de recursos financeiros. $\mathrm{O}$ conjunto inclui camisetas oficiais da escola, com estampas de referências ao enredo a ser apresentado no desfile, assim como CDs e DVDs, entre outros artigos oferecidos à compra pelo público interessado.

Certos tipos de material são também (até majoritariamente) doados, segundo informação registrada em entrevista com o presidente da escola. $\mathrm{O}$ motivo tem a ver com estratégia de marketing desenhada para promover a instituição. Esse procedimento é bastante comum entre as escolas de samba, de uma maneira geral, pelo que foi possível captar durante a pesquisa.

Não somente elementos tangíveis integram o rol de objetos distribuídos. Também pertence a esse segmento da cadeia produtiva do Carnaval o direito de imagem - envolvendo o próprio nome da escola, que se torna, assim, apto a ser referido/publicado em páginas na internet, revistas e jornais. A utilização desses elementos depende, naturalmente, de autorização.

Papel central nesse processo é desempenhado pela Liga das Escolas de Samba de Florianópolis (LIESF). É essa entidade que coordena a divulgação, por meio de contratos individuais firmados com as escolas, funcionando, assim, como "membrana" entre órgãos importantes da ossatura do Carnaval: as escolas de samba, de um lado, e os meios de comunicação, de outro. A LIESF negocia os termos e celebra contratos com os vários canais de divulgação, uma função especialmente estratégica no tocante à transmissão televisionada do desfile.

Essa transmissão permite, ao lado do comparecimento do público à Passarela do Samba Nego Quirido (local no centro de Florianópolis, no aterro da Baía Sul, onde as escolas de samba se apresentam, com ingressos comprados pela internet e em lojas da cidade), a concretização da etapa final do ciclo inteiro de preparação (ou produção) do Carnaval: o "consumo" do 
desfile. É para esse ato derradeiro que se enlaçam e se encadeiam, durante meses, diferentes decisões e procedimentos, envolvendo numerosas pessoas, representando muitos gastos e mobilizando diversas esferas de relações.

Mas ocorre "consumo" do samba e da agitação típica do Carnaval já antes do clímax representado pelo desfile oficial. Refere-se aqui aos ensaios necessários para que ajustes sejam promovidos e o samba seja "inoculado". E isto não envolve somente os integrantes da escola, pois a abertura ao público externo costuma ser a regra. A Protegidos tem realizado esses ensaios tanto no seu próprio barracão como em praças e outros espaços da cidade, utilizados com o consentimento da administração pública.

A Protegidos reduziu os ensaios abertos nos últimos anos, para número não superior a três. O principal motivo é que a vinculada arrecadação de recursos, proporcionada quando da utilização do barracão, não é suficiente para bancar o próprio evento específico, quanto mais para contribuir efetivamente ao financiamento do Carnaval da escola. Assim, recentemente, a prática foi limitada ao processo de escolha do samba enredo (o que significa dois eventos) e, quando a escola vence o concurso do desfile oficial, à chamada "Feijoada da Campeã", em comemoração ao título. Há também projeções extramuros da escola, pela participação do Grupo Show (alguns ritmistas e passistas) e de segmento da bateria em diferentes festas, um assunto tratado posteriormente.

\section{INTERAÇÕES E REFLEXOS SOCIOECONÔMICOS LOCAIS NA PRODUÇÃO DO CARNAVAL}

Produzir Carnaval em escolas de samba é tarefa onerosa em tempo e, sobretudo, em dinheiro. A visão geral proporcionada no artigo não permite dúvida sobre isso, tantos são os materiais e serviços profissionais exigidos. Assim, em pesquisa sobre o assunto, indagar sobre os recursos necessários à colocação da escola na avenida, para o desfile que representa o ponto culminante de um esforço de meses, é iniciativa natural e incontornável.

Colocada a integrantes da diretoria da Protegidos a pergunta sobre a origem dos recursos financeiros, obteve-se a informação de que vários são as instituições e agentes que contribuem. O Governo do Estado de Santa Catarina e a Prefeitura Municipal de Florianópolis perfilam-se como fontes principais. 
Também há auxílio de patrocinadores, na forma de empresas privadas, algo nem sempre assegurado e que tampouco representa ajuda financeira em todas as ocasiões. Quando acontece patrocínio nesses termos, o costume é formar uma parceria escorada em acordo sobre a venda das fantasias. Esta, assinale-se, é geralmente realizada através de página na internet destinada à aquisição on line, mas também ocorre de forma direta na secretaria da escola, instalada no próprio barracão.

$\mathrm{Na}$ parceria, o patrocinador propõe-se a participar da comercialização das fantasias não encaminhadas à doação. A doação, cabe assinalar, geralmente beneficia pessoas que ajudaram a escola voluntariamente, em qualquer tipo de serviço que represente necessidade nesse sentido, desde tarefas muito gerais até a contagem das fantasias e adereços no controle final para o desfile. Porém, segundo informado, a doação só acontece nas vezes em que a escola não consegue atingir o número mínimo de integrantes para o desfile. A Protegidos tem desfilado com cerca de 2.000 integrantes.

Os ganhos tendem a ser recíprocos nesse tipo de arranjo, pois o patrocinador logra ser referido no desfile, o que representa exposição com formato de marketing, e a escola tem diminuídas as chances de não conseguir vender, ela própria, as fantasias produzidas. Pelo que se conseguiu apurar, a Protegidos considera tratar-se de um importante auxílio, ainda que sem tradução em disponibilidade financeira direta.

Cabe também indicar que as vendas das fantasias tendem a espelhar a conjuntura sobretudo econômica da cidade, o que inclui a maior ou menor presença de turistas, entre outros aspectos. Essa restrição ilustra um vínculo aparentemente geral entre cultura e economia, conforme sublinhado por Florissi e Waldemar (2007), pelo qual a situação da segunda (no país, na região, na cidade) determina o peso da primeira (na forma de dispêndios, por exemplo) no dia a dia das pessoas, mesmo que estas atribuam importância aos produtos e serviços culturais e encontrem nestes uma fonte de satisfação.

O custo do Carnaval da Protegidos, considerando a experiência do desfile de 2014, atinge mais ou menos R\$ 1,4 milhão. Aproximadamente metade desse montante refere-se às despesas com mão de obra e a outra metade é dirigida aos gastos com o material necessário à produção (fantasias, adereços, carros alegóricos). Deve-se sublinhar que o custo total depende do tema - traduzido no enredo - escolhido pela escola para a "narrativa" 
do desfile. Alguns assuntos exigem bem menos do que a apontada quantia de R\$ 1,4 milhão. Outros, implicando fantasias mais luxuosas e elaboradas, requerem muito mais. Também em relação a isso se revela o caráter estratégico da escolha do enredo.

Aspecto importante do debate sobre economia da cultura, como campo de reflexão que exibe pontos de contato com a questão do desenvolvimento na escala local, incluindo a problemática das políticas de promoção, tem a ver com a geração de oportunidades de trabalho nas correspondentes atividades. Assim, merece destaque a informação, obtida na pesquisa de campo, de que a produção do Carnaval da Protegidos representa a mobilização direta de 140 trabalhadores em média, com alguma variação ao longo dos anos e, certamente, também nos meses em que se dá a preparação do desfile, nas várias etapas da cadeia produtiva.

A Tabela 1 apresenta os postos de trabalho vinculados à produção do Carnaval dessa escola, nas diversas funções do processo. A informação refere-se à preparação do Carnaval de 2014, do mesmo modo que o dimensionamento do custo antes referido. Mas, pelo que se apurou, a estrutura pouco se altera entre os vários carnavais.

Tabela 1 - Número e natureza dos postos de trabalhos ligados à produção do Carnaval na Escola de Samba Protegidos da Princesa - situação do Carnaval de 2014

\begin{tabular}{|l|r|}
\hline \multicolumn{1}{|c|}{ Funções/Setor } & \multicolumn{1}{c|}{$\mathrm{N}^{\circ}$ de trabalha-dores } \\
\hline “Aderecistas" & 17 \\
\hline Administrativo & 3 \\
\hline Auxiliar de serviços gerais & 3 \\
\hline Carnavalesco & 1 \\
\hline Casais de mestre sala e porta bandeira & 6 \\
\hline Contador & 1 \\
\hline Coordenador de carros alegóricos & 1 \\
\hline Coordenador das "aderecistas" & 1 \\
\hline Costureiras & 5 \\
\hline Diretores de bateria & 8 \\
\hline Empurradores de carros na avenida & 60 \\
\hline Equipe de Parintins para os carros alegóricos & 15 \\
\hline Intérpretes (cantores) & 8 \\
\hline
\end{tabular}




\begin{tabular}{|l|r|}
\hline \multicolumn{1}{|c|}{ Funções/Setor } & \multicolumn{2}{c|}{$\mathrm{N}^{\circ}$ de trabalha-dores } \\
\hline Iluminação dos carros durante o desfile & 5 \\
\hline Músicos (cavaquinho, violão) & 4 \\
\hline Transportador de materiais e produtos & 2 \\
\hline Total & 140 \\
\hline
\end{tabular}

Fonte: elaboração própria com base nas informações disponibilizadas pela diretoria administrativa da Escola de Samba Protegidos da Princesa

A categoria mais numerosa é a dos empurradores de carros alegóricos durante o desfile. Porém, a respectiva tarefa corresponde a um único momento na cronologia da produção do Carnaval: o desfile em si. A segunda modalidade em número é a das "aderecistas", cujo trabalho desenrola-se no tempo. Depois aparecem os trabalhadores da equipe proveniente do município amazônico de Parintins, composta por soldadores, serralheiros, decoradores e escultores, responsável pela construção dos carros alegóricos. Também representam números expressivos as funções de diretor de bateria e de intérprete do samba, cujo envolvimento é constante, até pelas exigências de ensaio, podendo-se dizer o mesmo sobre os casais de mestre sala e porta bandeira. As costureiras, como informado, totalizam cinco profissionais engajadas de forma direta, embora vínculos de terceirização, não computados nesta visão geral, surjam com frequência. Todas essas funções são remuneradas.

Ao lado desses profissionais, registra-se igualmente a atuação de voluntários. O número atinge perto de trinta pessoas, que de forma espontânea se articulam, por exemplo, antes do desfile para contar e conferir as fantasias no barracão. Essa é uma atividade de pura manifestação de apreço pela escola de samba, reflexo do entendimento da sua importância (em termos culturais e outros) para a comunidade e sua trajetória.

Informações como essas sugerem os reflexos econômicos e sociais que a produção de uma festa como o Carnaval há de provocar no plano da sociedade local. Esse é o caso, mais especificamente, nas várias comunidades que, direta e intensamente envolvidas, nutrem relações de vizinhança ou proximidade e, possivelmente, compartilham aspirações e cultuam valores mais ou menos comuns, ligados, por exemplo, à história local.

A Protegidos é somente uma das escolas que participam do Carnaval de Florianópolis. As outras são, pela programação do Carnaval de 2015: 
Embaixada Copa Lord, Consulado, Unidos da Coloninha, União da Ilha da Magia e Dascuia, esta a mais nova incorporação ao chamado "grupo especial". Em todas, o segundo semestre de cada ano é período de febris atividades de preparação, com o que isso significa em mobilização de recursos e de pessoas, como permite entrever a relatada experiência da Protegidos.

Há igualmente escolas de samba que compõem o chamado "grupo de acesso", com desfile em data específica, cujo Carnaval é igualmente produzido na órbita comunitária, envolvendo atividades de natureza semelhante - não obstante a menor escala - à registrada na pesquisa sobre a Protegidos. $\mathrm{E}$, naturalmente, existem numerosos blocos de sujos, de maior ou menor tamanho, e grupos de amigos e/ou formados por relações de vizinhança, em diferentes ambientes da cidade, que igualmente fazem fabricar fantasias e adereços e compram instrumentos musicais não raramente de segunda mão e recuperados por mão de obra profissional.

Em suma, em ambientes urbanos que cultivam a vivência coletiva do Carnaval, nos moldes do que ocorre em Florianópolis (e, obviamente, também no Rio de Janeiro, entre outros lugares), falar dessa festa corresponde a referir a um importante segmento da economia da cultura. Significa, da mesma forma, tangenciar a temática da dinamização econômica local, mesmo que grande parte dos insumos e matérias primas utilizados na produção do Carnaval das escolas de samba, como se observou na Protegidos, tenha origem (muito) distante.

Os múltiplos serviços envolvidos nas atividades da cadeia produtiva, nas suas várias etapas, reverberam localmente, na órbita da cidade e, mais especificamente, no seio das comunidades. Portanto, aludir a uma possível contribuição ao desenvolvimento local, em debate sobre a economia do Carnaval, não parece procedimento despropositado.

Amplia a importância do assunto o fato de o Carnaval ocorrer durante a alta temporada turística. Florianópolis, como é reconhecido, representa um dos mais destacados polos receptores de turistas do Brasil (LINS, 2007), e o Carnaval tanto contribui para a atratividade local quanto dela usufrui, pelo maior afluxo aos desfiles. Isso ressoa em maior consumo e injeção de recursos na economia.

Mas é importante olhar além da dimensão mais tangível desse processo. Pelo menos na Protegidos, fabricar o Carnaval e protagonizar o evento que 
é a culminação de um duradouro e extenuante esforço - o desfile - são atividades com sentido de, nas palavras do presidente da escola, em entrevista durante a pesquisa de campo, resgate da autoestima das comunidades envolvidas. Há, com efeito, muito de simbolismo nessa relação com o Carnaval.

O envolvimento das comunidades aparece na participação no próprio desfile, nas várias maneiras como isso pode acontecer. Mostra-se também no engajamento à produção material do festejo, querendo isto referir, com grande destaque, às atividades de costureiras e "aderecistas", por exemplo. Contudo, tomar parte nessa dinâmica significa mais do que auxiliar na preparação de um evento que tem na pressão do calendário uma fonte de grande excitação e agitação. A leitura (entusiasmada) do presidente é que cada Carnaval dá sequência a um projeto de escola de samba marcado pelo gradualismo nas suas conquistas.

Essas conquistas exibem diversas dimensões, tendo o destaque recaído, durante a entrevista, nas de cunho cultural, artística e social. Assim, o desfile oficial do Carnaval, embora represente o ápice de trajetórias anuais com duração de pelo menos meio ano, não esgota o "sentido" da Protegidos, segundo sublinhado. O mais importante papel da escola, pelo depoimento registrado, seria promover a inclusão sociocultural dos seus integrantes, quer dizer, da(s) comunidade(s) que representa(m) a sua base social.

Esse propósito permeia conjunto de atividades desenvolvidas permanentemente no âmbito da agremiação. A escolinha de mestre sala e porta bandeira, frequentada por muitos jovens aspirantes a tais posições na escola de samba ou simplesmente interessados em aprender a dança, funciona em sintonia com tal princípio.

Pode-se dizer o mesmo com respeito ao Grupo Show da Protegidos, criado em 2005. De estrutura flexível, formado por ritmistas jovens e por representantes da chamada corte da escola, incluindo rainha de bateria, cidadão e cidadã samba e casal de mestre sala e porta bandeira, o grupo faz apresentações em eventos públicos, festas de casamento e bailes de formatura, entre outros, divulgando a agremiação e ajudando a "fixá-la" ainda mais na atmosfera da cidade. O critério de juventude para definir quem participa mira simultaneamente a renovação dos contingentes envolvidos e a continuidade das interações comunitárias em torno da escola, além de fortalecer o seu caráter de instrumento de inclusão social para os jovens. 
É importante destacar também o departamento feminino da Protegidos. Criado há décadas, representa fonte de contínua ajuda em funções cotidianas, como na preparação de refeições para os que se engajam na produção do Carnaval durante a escalada que culmina no desfile. Esse departamento também promove a escola ao participar de eventos que possam resultar em melhorias para as comunidades implicadas, especificamente as do Maciço Central de Florianópolis, mais particularmente no Morro do Mocotó.

O "enraizamento" da Protegidos no ambiente sociocultural local atinge, do mesmo modo, as atividades da ala dos compositores. Atuando continuamente, na criação voltada ao desfile e também produzindo obras variadas de samba, esse segmento da escola tem composto para blocos de rua e contribuído musicalmente até para campanhas publicitárias.

Cabe uma menção especial à velha guarda da escola, reduto de preservação da história e tradição da Protegidos. Sua existência foi formalizada em fevereiro de 2005 - com a denominação Galeria da Velha Guarda -, o que favoreceu a execução de projetos enfeixados no seu Programa de Ação Social. As correspondentes atividades envolvem participação direta e indireta em vários eventos na cidade e intercâmbio sociocultural em diversas frentes, especialmente com entidades do Rio de Janeiro. Nas ações sobressaem encontros com comunidades do Morro do Mocotó e Morro da Queimada e visitas a instituições de saúde e de abrigo a idosos e carentes.

Possuindo um grupo musical próprio, a Velha Guarda também faz apresentações em acontecimentos beneficentes, objetivando, por exemplo, arrecadar fundos para edificar prédio para pacientes infantis e juvenis portadores de câncer e para abrigar seus familiares, oriundos do interior de Santa Catarina. A Velha Guarda igualmente atua dessa maneira em datas comemorativas (Páscoa, Dia das Crianças, Natal) e nas que formam o calendário turístico estadual, como as festas de outubro, no Vale do Itajaí (Oktoberfest, Fenarreco) e em Florianópolis (Festa Nacional da Ostra).

\section{CONSIDERAÇÕES FINAIS}

O Carnaval perfila-se como importante elemento da economia da cultura no Brasil. É assim em escala nacional, com realce para as escolas de samba e outras agremiações (como os grandes blocos, em várias regiões) que 
arregimentam numerosos participantes e mobilizam vultosas quantias. É assim em Florianópolis, onde o modelo do "Carnaval espetáculo", adotado por osmose da experiência carioca, representa "fabricação" do entretenimento carnavalesco que se estende por meses, canaliza muito dinheiro e trabalho e tem como ápice o desfile, na culminância do calendário oficial do festejo.

O estudo específico sobre a escola de samba Protegidos da Princesa, desenhado e executado à luz da noção de cadeia produtiva, mostra o modus operandi nas etapas que conduzem à oferta do produto final. Graças à pesquisa direta que se pôde efetuar, aspectos importantes são ressaltados e informações que permitem formar uma ideia sobre as implicações das atividades realizadas são oferecidas. A inescapável conclusão é que a Protegidos, e isto pode ser estendido às demais escolas que integram o Carnaval de Florianópolis, é um importante agente da economia da cultura nessa cidade e na sua região.

Os reflexos socioeconômicos e culturais, principalmente em escala comunitária, e o interesse - que provavelmente se manifesta nas outras escolas e suas respectivas comunidades - também em aspectos intangíveis e de cunho simbólico, como o resgate da autoestima (frisado pelo presidente da Protegidos), autorizam considerar que a problemática da produção e realização do Carnaval, nos moldes explorados no artigo, deve ter lugar no debate sobre o desenvolvimento em nível local, no plano da cidade.

\section{CARNIVAL PRODUCTION IN ESCOLAS DE SAMBA: AN ESSAY INSPIRED BY THE DISCUSSION ON CULTURAL ECONOMICS}

\section{Abstract}

Carnival has an outstanding presence in the Brazilian cultural landscape and economy, due to its historical presence, its meaning specially in large towns - where the escolas de samba prepare their show during several months, motivated by disputes in the official parades - , the social involvement in many communities and the huge resources employed. The article looks at a specific question concerning this subject: the production of the Carnival show of Protegidos da Princesa, the oldest escola de samba of Florianópolis. The text is mostly based on field research carried out at 
Protegidos da Princesa in the second semester of 2014. The segments of the production chain are object of detailed description, and some social and economic effects of the parade preparation, in the communities involved, are looked upon and discussed.

Keywords: Escolas de samba; Cultural economics

\section{JEL Classificaction: Z19}

\section{REFERÊNCIAS}

BENHAMOU, F. A economia da cultura. Cotia: Ateliê Editorial, 2007.

CABRAL, O. R. Nossa Senhora do Desterro. Memória I. Florianópolis: Imprensa da Universidade Federal de Santa Catarina, 1972.

COLAÇO, T. L. O carnaval no Desterro: século XIX. Florianópolis, 1988. Dissertação (Mestrado em História) - Universidade Federal de Santa Catarina.

DANTAS, A.; KERTSNETZKY, J.; PROCHNIK, V. Empresa, indústria e mercados. In: KUPFER, D.; HASENCLEVER. L. (Orgs.). Economia industrial: fundamentos teóricos e práticos no Brasil. Rio de Janeiro: Campus, 2002, p. 23-41.

FEIJÓ, C.; NAZARETH, A. Artesãos da Sapucaí. São Paulo: Olhares, 2011.

FLORISSI, S.; WALDEMAR, F. S. Economia da cultura: uma revisão da literatura. In: VALIATI, L.; FLORISSI, S. (Orgs.). Economia da cultura: bem-estar econômico e evolução cultural. Porto Alegre: Editora da UFRGS, 2007, p. 11-28.

FRIQUES, M. S. O escopo da economia criativa no contexto brasileiro. REDIGE, v. 4. n. 1, p. 1-16, 2013. 
JAMESON, F. Pós-modernismo: a lógica cultural do capitalismo tardio. 2.ed. São Paulo: Ática, 1997.

LEOPOLDI, J. S. Escola de samba, ritual e sociedade. Petrópolis: Vozes, 1978.

LINS, H. N. Interações, aprendizagem e desenvolvimento: ensaio sobre o turismo em Florianópolis. Turismo - Visão e Ação, v. 9, n. 1, p. 107-120, 2007.

LINS, H. N. Cidades fractais: a Ilha da Magia e seus alquimistas. Pesquisa \& Debate, v. 22, n. 1, p. 95-117, 2011.

MARGLIN, S. A.; SCHOR, J. B. (Eds.). The golden age of capitalism: reinterpreting the postwar experience. Oxford: Oxford University Press, 1990.

MIGUEZ, P.; LOIOLA, E. A economia do carnaval da Bahia. Bahia Análise \& Dados, v. 21, n. 2, p. 285-299, 2011.

PRESTES FILHO, L. C. (Coord.). Cadeia produtiva da economia do carnaval. Rio de Janeiro: E-papers, 2009.

QUEIROZ, M. I. P. de. Carnaval brasileiro: o vivido e o mito. São Paulo: Brasiliense, 1992.

RAMOS, A. A. Carnaval da Ilha. Florianópolis: Papa-livros, 1997.

ROUET, F. L'approche économique de la culture: esquisse d'un bilan. Culture \& Recherche, 68, p.3-7, 1998.

SEBE, J. C. Carnaval, carnavais. São Paulo: Ática, 1986.

SISTEMA de Informações e Indicadores Culturais 2003-2005. Estudos e Pesquisas - Informação Demográfica e socioeconômica n. 22. Rio de Janeiro: IBGE/Ministério da Cultura, 2007. 
SISTEMA de Informações e Indicadores Culturais 2007-2010. Estudos e Pesquisas - Informação Demográfica e socioeconômica n. 31. Rio de Janeiro: IBGE/Ministério da Cultura, 2013.

SODRÉ, M. Samba, o dono do corpo. Rio de Janeiro: Mauad, 1998.

TOLILA, P. Cultura e economia: problemas, hipóteses, pistas. São Paulo: Iluminuras: Itaú Cultural, 2007.

TRAMONTE, C. de A. A pedagogia das escolas de samba de Florianópolis: a construção da hegemonia cultural através da organização do carnaval. Florianópolis, 1995. Dissertação (Mestrado em Educação) - Universidade Federal de Santa Catarina. 